\title{
TRANSFORMASI PENDIDIKAN SENI DI TAMAN SISWA
}

\author{
Oleh: Unggul Sudrajat*
}

\begin{abstract}
The art paradigm that uses the Kancil story as a method of introducing moral values certainly has its own uniqueness and purpose. These two different views of the KPK and Tamansiswa are very contradictive, the same source gets the opposite interpretation. Therefore, the story of Kancil is interesting to study regarding its feasibility as one of the teaching materials in school. This paper will reveal the view of education in Taman Siswa about the Kancil story, specifically about Sendratari composed by Ki Hadi Sukatno which was studied through qualitative research with a discussion of descriptive analysis approach. The results of the study revealed the art transformation in Taman Siswa by explaining how educational facilities must be dynamic along with the development of the child's nature. Through dance, music, and drama movements collected in Sendratari "Mouse deer stealing Cucumbers", Ki Hadi Sukatno was able to implement the concept of the Among System created by Ki Hadjar Dewantara. The use of Kancil stories as a means of education must be sorted out which matches the basic or secondary level.Therefore, it is necessary to have a method that matches the character so that it finds the moral value implied through the fabric of the story.
\end{abstract}

Keywords: Mousedeer, dance, Hadi Sukatno, Tamansiswa, Ki Hadjar Dewantara

\begin{abstract}
ABSTRAK
Paradigma kesenian yang menggunakan cerita Kancil sebagai metode pengenalan nilai-nilai moral tentu memiliki keunikan dan tujuan tersendiri. Dua pandangan berbeda dari KPK dan Tamansiswa ini sangat kontradiktif, sumber yang sama mendapat penafsiran yang bertolak belakang. Maka dari itu, cerita Kancil menarik untuk dikaji terkait kelayakannya sebagai salah satu bahan ajar di sekolah. Tulisan ini akan mengungkapkan pandangan pendidikan di perguruan Taman Siswa terhadap cerita Kancil, secara khusus tentang sendratari gubahan Ki Hadi Sukatno yang dikaji melalui penelitian kualitatif dengan pembahasan pendekatan analisis deskriptif. Hasil dari penelitian mengungkapkan trasformasi seni di perguruan Taman Siswa dengan menjelaskan bagaimana sarana pendidikan harus dinamis seiring dengan perkembangan alam anak. Melalui gerak tari, olah swara, dan seni peran yang dihimpun dalam sendratari Kancil mencuri timun, ki Hadi Sukatno mampu mengimplementasikan konsep sistem among yang dibuat oleh Ki Hadjar Dewantara. Penggunakan cerita Kancil sebagai sarana pendidikan harus dipilah mana yang cocok dengan jenjang dasar atau menengah. Maka dari itu perlu metode yang sesuai dengan karakter sehingga menemukan nilai moral yang tersirat lewat jalinan cerita.
\end{abstract}

Kata Kunci: Kancil, Sendratari, Hadi Sukatno, Tamansiswa, Ki Hadjar Dewantara

*Peneliti di Pusat Penelitian Kebijakan Pendidikan dan Kebudayaan Badan Penelitian dan Pengembangan Kementerian Pendidikan dan Kebudayaan. Email:unggul.sudrajat@kemdikbud.go.id 
PENDAHULUAN

Pada tahun 2015, Komisi Pemberantasan Korupsi (KPK) mengungkapkan bahwa dongeng kancil merupakan kisah yang tak layak diajarkan di sekolah. Hal ini disebabkan dongeng kancil memuat sikap buruk kancil yang diasumsikan selalu menang di akhir cerita. Dalam beberapa cerita ada fragmen Kancil mencuri timur, bohong kepada rekan-rekannya, dan tidak pernah tertangkap saat berbuat kesalahan. Secara normatif KPK melihat ini sebagai sumber pengajaran yang bermasalah. Dalam harian Sindonews pada tanggal 26 Maret 2015 Guntur Kusmeiyano selaku pimpinan Pelaksana Harian (PLH) Direktur Dikyanmas KPK menyatakan bahwa kisah Kancil mengajarkan anak untuk berbohong dan mencuri (Ispranoto, 2015, p. 14). Tetapi fakta lain, Perguruan Taman Siswa Yogyakarta yang dipimpin oleh Ki Hadjar Dewantara waktu itu justru memakai kisah Kancil sebagai metode pengajaran budi Pekerti. Ki Hadi Sukatno sebagai salah satu pamong Taman Siswa menggubah cerita tersebut menjadi sendratari dalam bahasa Indonesia.

Cerita binatang atau fabel yang mengandung ajaran, umum terdapat di mana-mana. Setiap daerah mempunyai seekor binatang yang merupakan tokoh utama (Dananjaja, 2002, p. 3). Di daerah Toraja misalnya, tokoh utamanya adalah burung hantu, sedangkan di Jawa dan Sumatra adalah sang Kancil atau pelanduk. Salah satunya perintis penelitian tentang Kancil adalah Kern (1880, pp. 341-348), dalam penelitian tersebut menjelaskan keberadaan serat Kancil yang ada dalam beberapa koleksi di Jawa. Serat Kancil di Jawa ini juga terdiri dari beberapa versi. Penelitian lanjutan dilakukan Mc. Kean (1971, pp. 71-84) mengungkapkan beberapa varian kisah Kancil di Asia Tenggara, secara khusus yang bersumber dari naskah Melayu, Jawa, dan Aceh. Dalam penelitian tersebut cerita Kancil yang beredar secara lisan di Jawa dibukukan pada abad ke-19. Cerita Kancil banyak dibukukan dan dicetak ulang $\mathrm{H}$. Buning Yogyakarta, H. Benjamin Semarang, G.T.C Van Dorp Semarang, dan lain-lain. Perkembangan kesenian yang berbasis dongeng Kancil dimulai dengan keberadaan wayang Kancil era Kasunanan Giri (1478-1688). Wayang Kancil muncul kembali oleh R.M Sajid di Surakarta pada tahun 1925, oleh Bambang Murtiyoso pada tahun 1978, dan Ki Ledjar Subroto pada tahun 1980 (Pursubaryanto, 1996, pp. 12-14). Pada 
tahun 1954, Ki Hadi Sukatno membuat sebuah sendratari anak-anak berjudul “Kantjil Mentjuri Timun”. Paradigma kesenian yang menggunakan cerita Kancil sebagai metode pengenalan nilainilai moral tentu memiliki keunikan dan tujuan tersendiri. Dua pandangan berbeda dari KPK dan Tamansiswa ini sangat kontradiktif, sumber yang sama mendapat penafsiran yang bertolak belakang. Maka dari itu, cerita Kancil menarik untuk dikaji terkait kelayakannya sebagai salah satu bahan ajar di sekolah. Tulisan ini akan mengungkapkan pandangan pendidikan di perguruan Taman Siswa terhadap cerita Kancil, secara khusus tentang sendratari gubahan Ki Hadi Sukatno.

\section{METODE PENELITIAN.}

Tulisan ini menggunakan penelitian kualitatif dengan pendekatan analisis deskriptif. Menurut Keirl dan Miller dalam Moleong (2004, p. 131), penelitian kualititatif adalah tradisi tertentu dalam ilmu pengetahuan sosialyang secara fundamental bergantung pada pengamatan, manusia, kawasannya sendiri dan berhubungan dengan bahasa dan peristilahahnya. Peneliti merupakan instrument kunci, penelitian gabungan dan analisis data induktif. Penelitian ini mengumpulkan data-data terkait cerita kancil dan implementasinya di perguruan Taman Siswa. Analisis deskriptif dari penelitian ini menghubungkan proses dan pengaruh dalam proses penggunakan Sendratari sebagai media pendidikan di era Ki Hadi Sukatno.

\section{HASIL DAN PEMBAHASAN}

Dalam semua versi cerita kancil berbahasa Jawa, ceritanya dapat dilihat sebagai suatu siklus yang menceritakan seluruh riwayat hidup sang Kancil sejak lahir sampai meninggalnya. Salah satu versi Serat Kancil yang tertua adalah Serat Kancil Amongsastra (selanjutnya disingkat SKA) karangan Kyai Rangga Amongsastra, seorang penulis Kadipaten selama pemerintahan PB V di Surakarta. Serat kancil tersebut dikarang pada tahun 1822. Atas usaha Dr. W. Palmer van den Broek, SKA dicetak pada tahun 1878 dengan judul Serat Kancil anyariyosaken lelampahahanipun kancil, kidang, lan sapanunggilanipun satowana. Buku ini diterbitkan kembali pada tahun 1889 dengan perantaraan D.F van der Pant, sesudah mendapat perbaikan. SKA telah digubah dalam bentuk prosa oleh $\mathrm{Ki}$ Padmasusastra (Ng. Wirapustaka) dengan judul Serat Kancil Tanpa Sekar, 
Lampah-lampahipun Kabayan Kancil, diterbitkan oleh H. A Benjamin di Semarang pada tahun 1909.

Serat Kancil lain yang juga merupakan buku induk adalah Serat Kancil yang diterbitkan oleh G.C.T van Dorp di Semarang pada tahun 1871, berjudul Serat Kancil, awit kancil kalahiraken ngantos dumugi pejahipun wonten ing nagari Mesir, mawi kasekaraken. Buku ini mengalami cetak ulang sebanyak dua kali yaitu pada tahun 1875 dan 1879. Pengarang teks versi ini tidak diketahui. Tentang masa penulisannya, Brandes berpendapat bahwa Van Dorp menerbitkan versi teks lama (Behrend, 1990, p. 326). Angka tahun 1871 yang termuat pada pupuh pertama edisi ini menunjukkan masa naskah pertama kali naik ke percetakan. Pada tahun 1881 F.L. Winter menyalin teks ini ke dalam bahasa Melayu, berbentuk prosa, dengan judul Lotgevallen van den kantjil in het Maleisch. Setahun berikutnya yaitu pada tahun 1882, ia menyalin dan menerbitkan teks yang sama dalam bahasa Jawa berbentuk prosa dengan judul Lotgevallen van den kantjil, geillustreed met 12 platen uit den poezie in proza overgebracht en voor de jeugd omgewerkt atau Serat dongeng anyariosaken lelampahanipun kancil kajarwekaken dening Tuwan F.L. Winter ing Surakarta, kangge waosan para lare, mawi rinengga ing gambuh bar 12 idji. Kedua buku tersebut diterbitkan oleh Penerbit Gimberg di Surabaya.

Serat Kancil Salokadarma merupakan buku induk lain. Serat ini pula yang terdapat dalam koleksi museum Dewantara Kirti Griya. Buku ini dikarang oleh Raden Mas Arya Sasraningrat, putra Pakualam di Yogyakarta, berangka tahun 1891. Serat Kancil ini banyak memuat penjabaran ngelmi kasampurnan. R.P. Natarata menggunakan buku tersebut sebagai sumber untuk menggubah Serat Kancil Kridamartana yang diterbitakan H. Buning pada tahun 1909. Setelah melihat naskah-naskah Serat Kancil koleksi Ruang Naskah FSUI nomor CL.57-62 ternyata masing-masing teks merupakan versi tersendiri (Behrend, 1990, p. 327). Menurut Philip Frick McKean (1971, p. 81), ada enam stuktur dari kisah Kancil yakni:

Six motifemes may be perceived in the Kantjil tales.

1. An opening description of a calm and harmonious universe.

2. A threat of danger confronts Kantjil.

3. Kantjil presents an alternative action. 
4. The enemy accepts the alternative action, because of his greedy motives.

5. The consequences of following Kantji versus alternatives are visited upon the enemy.

6. Harmony and calm return once again to Kantjil universe.

\section{Pendirian Taman Siswa}

Pada tahun 1921 - 1922 Suwardi Suryaningrat aktif dalam perkumpulan Selasa Kliwonan yang beranggotakan tokoh-tokoh politik, kebudayaan, dan kebatinan, yaitu : R.M. Sutatmo Suryokusumo Ki Sutopo Wonoboyo, Ki Pronowidigdo, Ki Prawirowiworo, RM. Gondoatmojo, B.R.M. Subono, R.M.H. Suryo Putro (paman Suwardi Suryaningrat), dan Ki Ageng Suryomataram. Sarasehan tersebut membahas kehidupan dan nasib bangsa Indonesia yang sengsara dan penuh penderitaan, dengan mencari jalan untuk menegakkan dan membina kepribadian bangsanya. Hasil analisisnya bercita-cita untuk "Memayu hayuning sarira, memayu hayuning bangsa”, dan "memayu hayuning bawana "(membahagiakan diri, bangsa, dan dunia). Mereka berpendapat bahwa citacita tersebut tidak bisa dicapai melalui pergerakan politik saja, tetapi harus dicapai dengan pendidikan rakyat serta memperbaiki jiwa dan mental bangsa. Akhirnya Sarasehan Slasa Kliwonan memutuskan: Ki Ageng Suryomataram bertugas menangani mendidik orang tua, dengan Ilmu Jiwa Kawruh Begja yang kemudian berkembang menjadi Kawruh Jiwa. Sedangkan Suwardi Suryaningrat dengan beberapa kawannya: R.M. Sutatmo Suryokusumo, Ki Pronowidigdo, R.M.H. Suryo Putro, Ki Sutopo Wonoboyo, Ki Cokrodirjo, dan BRM. Subono serta R.Ay. Sutartinah diserahi tugas menangani pendidikan anak-anak. Dengan pengalamannya bekerja sebagai guru di Perguruan Adhidarma milik kakaknya RM. Suryapranoto, akhirnya pada Senin Kliwon, 3 Juli 1922 Suwardi Suryaningrat dkk mendirikan Nationaal Onderwijs Instituut Taman Siswa di jalan Tanjung, Pakualaman, Yogyakarta (Sajoga, 1952, pp. 13-14).

Taman siswa membuka bagian Taman Anak atau Taman Lare, yaitu satuan pendidikan setingkat Taman Kanak-kanak (Taman Indria). Kemudian pada 7 Juli 1924 mendirikan Mulo Kweekshool setingkat SMP dengan pendidikan guru (4 tahun sesudah pendidikan dasar). Pada tahun 1928 tamatan Mulo Kweekshool dapat masuk 
AMS (Algemene Middelbare School) setingkat SMA Negeri hampir 70\%. Dengan kesuksesannya itu bangsa Indonesia tergugah semangat dan makin tebal rasa harga dirinya. Lahirnya Perguruan Nasional Tamansiswa mendapat sambutan luar biasa dari segala lapisan masyarakat. Setelah ditangani oleh pengurus yang bersifat kolektif kolegial yang disebut Instituutraad diperluas menjadi Hoofdraad (nama sekarang Majelis Luhur Persatuan Tamansiswa), dan ditegaskan bahwa pada 6 Januari 1923 Pergerakan Kebangsaan Taman Siswa dinyatakan sebagai "wakaf bebas". Lembaga ini diserahkan oleh Ki Hadjar Dewantara pada 7 Agustus 1930 kepada Yayasan Taman Siswa, yang berkedudukan di Yogyakarta. Ratusan Perguruan Tamansiswa tumbuh di mana-mana dijiwai oleh semangat cinta tanah air. Suwardi Suryaningrat dengan Tamansiswanya terkenal di mana-mana. Sang Pujangga Rabindranath Tagore dari Shanti Niketan, Bolpur India, dengan rombongan yang dipimpin Prof. Dr. Chatterjee dalam kunjungan ke Indonesia memerlukan datang di Yogyakarta untuk mengunjungi Perguruan Tamansiswa (Agustus 1927). Demikian pula Prof. Dr. R. Bunche (USA), seorang pelopor dalam memperjuangkan persamaan hak menikmati pendidikan bagi orang-orang Negro, tertarik untuk mempelajari gerakan Tamansiswa dalam memperjuangkan hak rakyat Indonesia untuk menikmati pendidikan bagi rakyat Indonesia (Tahun 1939).

Pada 3 Februari 1928 Suwardi Suryaningrat genap berusia 40 tahun menurut tarikh Jawa (5 windu) dan berganti nama Ki Hadjar Dewantara. Menurut Ki Utomo Darmadi, Hadjar : pendidik; Dewan : Utusan; tara : tak tertandingi. Jadi maknanya: Ki Hadjar Dewantara adalah Bapak Pendidik utusan rakyat yang tak tertandingi menghadapi kolonialisme (Sajoga, 1952, p. 15). Pergantian nama tsb. merupakan sublimasi misi hidup dari "Satriya Pinandita" menjadi "Pandhita Sinatriya" (Satriya yang sekaligus bersikap laku Pandhita-Pendidik, kemudian meningkat menjadi Pandhita-Pendidik yang secara simultan berjuang untuk menegakkan keadilan dan kebenaran $=$ misi utama Satriya). Tamansiswa sebagai salah satu lembaga pendidikan yang didirikan $\mathrm{Ki}$ Hadjar Dewantara telah berhasil meletakkan dasardasar pendidikan yang memerdekakan sekaligus meletakkan dasar-dasar bagi sistem pendidikan nasional. Kehadiran Ki Hadjar 
Dewantara dalam membangun

Tamansiswa memiliki spectrum sejarah nasional, yang tak luput dari stretegi kebudayaan yang digelutinya. Beliau menjadikan Trikon (Kontinyu, konvergen, konsentris) dalam proses kebudayaannya. Kontinyu: berkesinambungan dengan masa lalu, Konvengen: bertemu secara terbuka dengan perkembangan alam dan zaman. Terakhir Konsentris: menyatu dengan nilai-nilai kemanusiaan, dunia. Ki Hadjar Dewantara memang tidak pernah ragu menetapkan sistem dan model pendididkannya berbasis pada kebudayaan lokal-nasional. Beliau hendak mengangkat model pendidikan pribumi untuk menghadapi sistem pendidikan kolonial, selanjutnya digerakkan secara serentak untuk mencapai kemerdekaan nasional.

Ada empat strategi pendidikan Ki Hadjar Dewantara, Pertama: pendidikan adalah proses budaya untuk mendorong siswa agar memiliki jiwa merdeka dan mandiri; kedua : membentuk watak siswa agar berjiwa nasional, namun tetap membuka diri terhadap perkembangan internasional; ketiga: membangun pribadi siswa agar berjiwa pionirpelopor; dan keempat: mendidik berarti mengembangkan potensi atau bakat yang menjadi Kodrat Alam-nya masingmasing siswa.

Selama 37 tahun Ki Hadjar Dewantara memimpin dan mengasuh Perguruan Tamansiswa yang tersebar di seluruh Indonesia. Ki Hadjar Dewantara wafat pada tanggal 26 April 1959 di Padepokan Ki Hadjar Dewantara dan disemayamkan di Pendapa Agung Tamansiswa Yogyakarta. Jenazah Ki Hadjar Dewantara dimakamkan pada tanggal 29 April 1959 secara militer dengan Inspektur Upacara Kolonel Soeharto di makam Taman Wijaya Brata, Celeban, Yogyakarta. Ki Hadjar Dewantara meninggalkan seorang isteri Nyi Hadjar Dewantara dan 6 orang anak: Ni Niken Wandansari Sutapi Asti, Ki Subroto Aryo Mataram (Brigjend. TNI), Nyi Ratih Tarbiyah, Ki Sudiro Ali Murtolo (lahir 9 Agustus 1925), Ki Bambang Sokawati (lahir 9 Maret 1930) dan Ki Syailendra Wijaya (lahir 28 September 1932). Semua benda bersejarah, buku, surat, penghargaan, dan barang-barang perabot rumah tangga peninggalan Ki Hadjar Dewantara kini tersimpan di Museum Dewantara Kirti Griya J1. Tamansiswa No. 25 Yogyakarta. Museum ini menyimpan arsip-arsip terkait pendidikan seni di perguruan Taman Siswa. 


\section{Seni Sendratari di Taman Siswa}

Taman Siswa memiliki visi bahwa hanya ada perkembangan alami apabila anak dididik yakni sesuai dengan kondisi alam materi, bakat alam, dan kondisi alamnya. Dalam alam, pusat pendidikan utama terletak pada keluarga. Ayah dan ibu merupakan pendidik anak yang paling utama. Suatu pandangan alami tertentu untuk mendidik selalu terpusat pada ayah atau ibu. Pandangan ini menjadikan keluarga sebagai pusat pendidikan alami. Pandangan ini menghendaki sistem among dialihkan kepada Paguron, di sekolah. Dari sana Taman Siswa dalam organisasinya tampil sebagai "keluarga besar dan suci". Keluarga ini pada dasarnya berbeda dari keluarga alami.

Pendidikan kesenian hal penting bagi Perguruan Taman Siswa; melalui pendidikan kesenian dibangun karakter individu maupun sosial hingga kebangsaan. Pelaksanaan pendidikan di Taman Siswa berdasarkan asas sistem among. Sistem Among yang diterapkan kepada anak didik Taman Siswa, salah satu sistem pengajaran yang diberikan oleh Taman Siswa ke dalam bentuk kesenian. Ki hadjar Dewantara menyatakan mengutamakan kesenian nasional dengan menanam benih atau bekal budi pekerti (watak atau tabiat) yang akan merapatkan jiwa anak dengan kebangsaannya. Sedangkan mata pelajaran kesenian, digunakan untuk memasakkan jiwa dan raga anak, hingga kelak menjadi derajat manusia utama serta dapat menyusun perikehidupan yang pantas dalam masyarakat yang akan dipikul bersama-sama (Dewantara, 1977, p. 314).

Dalam buku Ki Hadjar Dewantara (1967, p. 311) yang berjudul Bagian II Kebudayaan ia menuliskan bahwa pelajaran seni suara dan seni musik itu mempunyai arti yang sangat besar, dapat orang simpulkan dari keterangan yang diberikan Sultan Agung, Kerajaan Mataram. Ki Hadjar Dewantara menyatakan tak akan mengakui keturunan Mataram sebagai keluarganya, bila mereka tidak memperlihatkan sastra gending. Istilah sastra adalah kesusatraan atau pengetahuan pada umumnya, dan gendhing diartikan seni suara dan musik Jawa yang bermaksud menghaluskan budi kita. Alat untuk mendapatkan kehalusan budi ini ialah halusnya pendengaran. Sebab halusnya panca indra kita berakibat halusnya manusia.

Anak-anak Jawa pada zaman dahulu itu kelihatan seolah-olah tidak mendapat pendidikan yang sebaik sekarang, akan 
tetapi pada hakikatnya anak-anak zaman dahulu itu mendapat pendidikan dari alam sendiri, sebab dalam segala tingkah laku mereka selalu menyanyi. Di dalam masyarakat Jawa ada empat macam lagu anak-anak Jawa yakni lagu dinyanyikan pada permainan-permainan yang bersifat keolahragaan, nyayian tidak untuk permainan olahraga, lagu yang dinyanyikan tidak bersamaan dengan permainan, dan nyanyian yang bersifat mendidik (Dewantara, 1967, p. 188)

Ki Hadjar Dewantara memandang Seni sebagai medium untuk "memasakkan jiwa dan raga anak, hingga kelak menjadi derajat manusia yang utama". Salah satu contoh yang menarik di Taman Siswa adalah pembelajaran Seni Sastra (Tulis dan Lisan), Sari Swara dan Sendratari dengan menggunakan salah satu versi Serat Kancil Salokadarma koleksi Museum Dewantara Kirti Griya. Cerita Kancil selain digunakan sebagai bahan ajar mendongeng di dalam kelas, teks ini juga digubah menjadi Sendratari oleh Ki Hadi Sukatno.

\section{Ki Hadi Sukatno Pelaksana Konsep Ki Hadjar Dewantara}

Ki Hadi Sukatno berkenalan dengan Taman Siswa saat ia belajar di
Taman Guru. Ia lahir pada tanggal $26 \mathrm{Mei}$ 1915 di Delanggu Klaten dari pasangan Raden Djojomartono yang juga keturunan dari Sunan Pakubuwana IV di Surakarta. Ki Hadi Sukatno akhirnya menjadi Pamong di Taman Siswa. Kemampuanya bermain gamelan menjadikannya salah satu seniman yang mewujudkan konsep-konsep Ki Hadjar Dewantara utamanya seni sebagai sarana pendidikan. Ia menciptakan banyak lagulagu untuk anak-anak, opera, lagu dolanan, dan lain-lain. Bagi Ki Hadi Sukatno, sarana pendidikan yang baik adalah dekat dengan lingkungan atau alam anak (Sukatno, 1956, p. 49).

Salah satu konsep dari Sistem Among yakni siswa mempraktekkan peran, gerak, tari, dan suara. Hal ini mampu meningkatkan kepekaan terhadap lingkungan dan masyarakat. Ini selaras dengan konsep Ki Hadjar Dewantara Tri Na (Tiga Na): Nonton (melihat/ mengamati), Niteni (mengingat/ menandai), dan Niru (mencontoh/ meniru). Beberapa langkah yang diambil Ki Hadi Sukatno adalah menggubah karya yang menjadi Langen Carita (Takwin, 2015). Pada tahun 1964, Ki Hadi Sukatno membukukan lakon Langen Carita untuk Taman Indria antara lain: Arya Penangsang, Bocah Lola, Jaka 
Tingkir, Aji Saka, Babat Alas, Kancil Nyolong Timun, Kethek lan Garuda. Menurut Pramutomo (2018, p. 333) Langen Carita adalah prototipe pengembangan Langendriyan yang diciptakan di era Hamengkubuwono VII. Karya Langen Carita yang digubah ke dalam bahasa Indonesia disebut juga dengan Sendratari dan Nyanyi.

Salah satu lakon yang digubah oleh Ki Hadi Sukatno adalah lakon Kancil Mencuri Timun. Lakon ini diadopsi dari cerita lisan dan manuskrip, lalu digubah menjadi Sendratari pada tahun 1964. Ki Hadi Sukatno menggubah fragmen Kancil mencuri timun menjadi tiga babak dan terdiri dari empatbelas lagu iringan. Lagu keempatbelas merupakan lagu berjudul Si Kancil karya ibu Soed yang populer dalam dunia pendidikan anak di Indonesia hingga saat ini. Sendratari dimulai dari cerita perjalanan rombongan Kancil yang pergi ke sebuah ladang timun, lalu anak-anak petani membuat orang-orangan untuk menakuti Kancil. Ada salah satu Kancil muda yang berkarakter pemberani dan banyak akal menjadi pemimpin rombongan itu. Awalnya rombongan Kancil takut mengikuti, karena ajakan kuat dari Kancil putra, akhirnya mereka bersama-sama menuju ladang Mentimun.
Fragmen kedua, mengisahkan anak-anak petani yang mencari cara untuk menangkap Kancil. Setelah itu anak-anak petani membuat boneka raksasa dilumuri getah. Selang beberapa waktu, datanglah rombongan Kancil, mereka terkejut melihat boneka raksasa. Tetapi Kancil muda menyadari bahwa itu hanya sekedar boneka.

Fragmen ketiga, Kancil muda memukul boneka raksasa itu. Lalu seluruh badannya lengket dengan boneka raksasa yang sudah dilumuri getah. Akhirnya tertangkaplah Kancil muda, anak-anak petani lalu keluar dari tempat pengintaiannya. Kancil yang tertangkap ramai-ramai dibawa pulang ke desa.

Dari cerita dalam Sendratari tersebut, Ki Hadi Sukatno memilih cerita Kancil yang tertangkap karena kejahatanya sebagai sumber penciptaan seni di Taman Siswa. Selain itu, cerita Kancil digubah ke dalam bahasa Indonesia. Menurut Ki Hadjar Dewantara (1967, pp. 495-509), alam bahasa terletak semua yang tersimpan, apa yang dimiliki rakyat dari nilai kebatinan. Bahasa sendiri akan memberi anak sebagai jalan masuk menuju ke hati rakyat. Bila pendidikan berjalan dengan baik, pasti akan terjadi pengalihan budaya. Penguasaan bahasa rakyat sendiri 
menjadi syarat pertama karena hanya dengan itu rakyat bisa merasakan kebudayaannya sendiri. Hal ini menjadi suatu syarat demi munculnya rasa kasih terhadap budaya sendiri, yang merupakan faktor penting dalam usaha untuk pengembangan budaya, menuju pengembangan lebih lanjut. Sehubungan dengan ini, dalam sistem among berlaku prinsip bahwa pendidikan harus dilaksanakan dalam bahasa ibunya sendiri. Terutama bagi anak kecil, penggunaan bahasa daerah dalam pendidikan dianggap sangat penting, karena pendidikan baru bisa hidup. Hantu, mitos dan legenda bisa dikisahkan kepada anak ketika mereka masih sangat peka. Jadi anak hidup dalam fantasinya dengan rakyatnya sendiri dan ikut terlibat dalam penilaian rohani sejauh daya tangkapnya memungkinkan.

Penggunaan bahasa ibu merupakan suatu tuntutan untuk meletakkan dasar yang kuat bagi proses berpikir. Jadi pendidikan dengan menggunakan bahasa asing diperlukan pada usia yang lebih tinggi, bila anak sudah mampu menguasai bahasa mereka sendiri. Di tingkat Taman kanak-kanak, masih belum ada pendidikan bahasa asing yang diberikan. Sistem among menganggap permainan anak memegang peranan penting dalam mendidik anak, karena semuanya terletak dalam jiwa anak itu sendiri. Hal ini sesuai dengan fantasi mereka dan dorongan bagi kegiatan dan gerak motorik mereka. Tidak ada yang lebih alami dari pada anak bisa memperoleh permainannya sendiri yang berasal dari lingkungannya sendiri. Jadi anak tetap berada dalam lingkup rakyatnya sendiri. Jika sebaliknya anak menerima permainan asing, maka akan tertanamkan inti pemisahan dari bangsanya sendiri. Melalui permainan nasional berbahasa nasional, pemikiran anak secara alami tumbuh bersama kehidupan rakyatnya. Hal ini menunjukkan bahwa pamong harus bijak mengambil cerita, sehingga tidak terjadi kesalahan penafsiran oleh siswa seperti yang ditakutkan oleh KPK. Dengan memerankan tokoh dalam Sendratari, siswa mampu menyelami kompleksitas permasalahan di kehidupan. Melalui seni, siswa mampu memngambi nilai moral dan cara bersikap.

Sejarah trasformasi seni di perguruan Taman Siswa ini menjelaskan bagaimana sarana pendidikan harus dinamis seiring dengan perkembangan alam anak. Melalui gerak tari, olah swara, dan seni peran yang dihimpun dalam 
sendratari Kancil mencuri timun, Ki Hadi Sukatno mengenalkan konsep tri-wira (wiraga, wirama, wiraga) kepada anakanak (Dewantara, 1977, p. 28). Di Taman Siswa perlu dibedakan tiga periode perkembangan anak sejak lahir sampai dewasa. Setiap periode mencakup waktu delapan tahun (windu). Windu pertama disebut zaman wiraga (mengikuti raga). Hal ini merupakan masa perkembangan fisik dan bagian tubuh lainnya. Windu kedua disebut zaman wicipta (alam pikir). Periode ini merupakan perkembangan daya intelektual anak, yang sangat mempengaruhi sifat pemahamannya. Windu ketiga disebut zaman wirama (keharmonisan). Ini merupakan masa penyesuaian dengan dunia luar, di mana anak akan menentukan tempat yang akan didudukinya di sana. Setelah masa ini, anak menjadi dewasa. Pada masa ini anak sudah mencapai usia sekitar 23 tahun. Melalui sendratari dan nyanyi ini, anakanak mempu menyelami alam jiwa, rasa dan pikirannya melalui peran yang dimainkan dengan segala kekuatan dan kecakapan (Sukatno, 1952, p. 58). Maka dari Ki Hadi Sukatno juga disebut sebagai pelaksana konsep sistem among Ki Hadjar Dewantara.

\section{KESIMPULAN}

Fragmen cerita Kancil digubah menjadi kompleks, penuh nilai dan hidup dalam satu rangkaian Sendratari sehingga kesesuaian jenjang usia dan materi ajar begitu penting. Hal ini digunakan untuk meminimalisir kesalahmaknaan anak terhadap materi ajaran terutama dongeng. KI Hadi Katno selalu menempatkan diri sebagai pamong yang akrab dengan berbagai jenjang siswanya, baik dari Taman Indria sampai dengan Taman Madya. Ia membuat berbagai lagu dolanan dan pakem opera yang disesuaikan dengan umur siswa. Dongeng Kancil bukan sekedar dongeng pengantar tidur belaka, melainkan lebih dari itu. Cerita pada serat ini cukup menghibur, namun harus dipilah mana yang cocok dengan jenjang taman Indria atau Taman Madya. Maka dari itu perlu metode yang sesuai dengan karakter sehingga menemukan nilai moral yang tersirat lewat jalinan cerita, nilai yang dimaksud terdiri dari dua nilai yaitu rukun dan hormat.

Adapun keadaan sosial budaya yang melatarbelakangi munculnya nilai tersebut adalah berkuasanya kolonial yang mengakibatkan pengaruh yang besar pada bidang ekonomi; sosial; budaya dan agama. Pengaruh tersebut 
menimbulkan penderitaan bagi rakyat terutama rakyat kecil, tingkat ekonomi kolonial mengalami pertumbuhan sedangkan masyarakat kecil mengalami penurunan. Di bidang sosial budaya terjadi perubahan terutama pada gaya hidup, akibat pengaruh barat, banyak masyarakat yang telah kehilangan ciri dan tradisinya. Di bidang agama, meski mengalami perkembangan namun diiringi dengan tumbuhnya ideologiideologi baru yang rentan konflik.

\section{DAFTAR PUSTAKA}

Behrend, T. (1990). Katalog naskah naskah Museum Sonobudoyo Yogyakarta. Jakarta: Djambatan.

Dananjaja, J. (2002). Folklor Indonesia: Ilmu gosip, dongeng, dan lainlain. Jakarta: Pustaka Utama Grafiti.

Dewantara, K. H. (1967). Bagian II Pendidikan. Yogyakarta: Majelis Luhur Taman Siswa.

Dewantara, K. H. (1977). Pendidikan. Yogyakarta: Majelis Luhur Persatuan Taman Siswa.

Ispranoto, T. (2015, Maret 3). Dongeng Si Kancil Dianggap Menyesatkan Oleh KPK. Bandung, Jawa barat, Indonesia: Sindonews.

Kelch, K. (2014). Becoming history. Taman Siswa and its (Master Thesis). Leiden: unpublish.

Kern, H. (1880). Losse Aanteek Eningen Op Het Boek Van Den Kantjil. Bijdragen tot de Taal-, Land- en
Volkenkunde van NederlandschIndië, 341348.

McKean, P. F. (1971). The Mouse-deer ("Kantjil") in Malayo-Indonesian Folklore: Alternative Analyses and the Significance of a Trickster Figure in South-East Asia. Asian Folklore Studies, Vol.30 No.1, 71-84.

McVey, R. T. (1967). Taman Siswa and the Indonesian National Awakening. USA: Southeast Asia Program Publications at Cornell University.

Moleong. (2004). Metode Penelitian Kualitatif. Bandung: Remaja Rosda Karya.

Pramutomo, R. (2018). Langen Carita Jaka Tingkir Opera Edukasi Anak: Kajian Etnokoreologi. Jurnal Seni dan Budaya, 332342.

Pursubaryanto, E. (1996). Seni pertunjukan wayang kancil dan kemungkinan pengembangannya di Indonesia. Jurnal Humaniora, 12-23.

Sajoga. (1952). Riwayat Perdjuangan Tamansiswa: 30 tahun 19221952. Yogyakarta: Majelis Luhur Taman Siswa.

Sukatno, K. H. (1952). Permainan Anak Sebagai Alat Pendidikan. In M. L. Tamansiswa, Buku peringatan Taman Siswa 30 tahun19221952. Yogyakarta: Majelis Luhur Tamansiswa.

Sukatno, K. H. (1956). Pendidikan Kesenian di Taman Siswa. PUSARA, 49.

Takwin, B. (Ed.). (2015). Mendidik Dengan Budaya: Refleksi 100 Tahun Pak Katno. Yogyakarta: unpublish. 